\title{
Que quadrilátero é? Licenciandos em matemática usando propriedades conhecidas no VMT com o GeoGebra
}

\section{João Carlos Fernandes Barreira}

Graduando em Matemática, Universidade Federal Rural do Rio de Janeiro (UFRRJ)

Bolsista de IC/CNPq/PROPPG

jcbarreira95@gmail.com

\section{Marcelo Bairral}

Professor, Universidade Federal Rural do Rio de Janeiro (PPGEduc e PPGEduCIMAT) www.gepeticem.ufrrj.br

mbairral@ufrrj.br

\section{Resumo}

Ambientes de geometria dinâmica podem constituir espaço para aprendizagem e desenvolvimento do pensamento científico. Eles permitem a construção e o manuseio de objetos matemáticos na tela do computador: a possibilidade de clicar, arrastar e transformar diferentemente uma figura, influencia qualitativamente na descoberta matemática. $\mathrm{O}$ objetivo deste artigo é ilustrar uma dupla de licenciandos interagindo no VMTcG na resolução de uma tarefa com os propósitos de construir um quadrilátero e analisar a sua natureza. Os dados foram coletados mediante tabelas geradas no ambiente, registros escritos, uso do VMT player, print de telas com construções no quadro branco ou na aba do GeoGebra e registros dos pesquisadores. As formas de convencimento sobre a natureza do quadrilátero construído estiveram basicamente embasadas em propriedades conhecidas por eles sobre o quadrilátero em análise. Resultados instigam sobre tipo de tarefa e estratégias de raciocínio usadas pelos interlocutores.

Palavras-chave: Geometria dinâmica. VMTcG. Licenciatura em matemática. Construção de quadriláteros.

\section{Which quadrilateral is it? Prospective mathematics teachers using knowing properties on VMT with GeoGebra}

\begin{abstract}
Dynamic geometry environments can be a space for learning and developing scientific thinking. They allow the construction and manipulation of mathematical objects on the computer screen, and the ability to click, drag and transform a figure differently qualitatively affects mathematical discovery. The purpose of this article is to report on part of an analysis of prospective mathematics teachers interacting in the VMTcG in solving a task with the purposes of building a quadrilateral and analyzing its nature. The data were collected through tables generated in the environment, the use of the VMT player, printscreen with whiteboard constructions or GeoGebra flap, and researchers' records. The ways of convincing concerning the nature of the quadrilateral were manly based on properties known by them about the quadrilateral under analysis. Results instigate about the type of task and strategies used by the interlocutors.
\end{abstract}

Keywords: Dynamic geometry. VMTwG. Prospective mathematics teachers. Construction of quadrilaterals. 


\section{Introdução}

Com as constantes transformações vividas pela educação há uma busca dos professores por métodos inovadores de ensinar. Na educação matemática esta procura não está sendo diferente. Uma delas é pelo uso de ambientes de geometria dinâmica (AGD) nos processos de ensino e de aprendizagem. Apesar de ainda serem poucos usados nas escolas, os AGD estão modificando a forma de aprender matemática, por exemplo, transformando a construção e a representação estática de uma figura, para formas dinâmicas e que constituem uma classe de figuras e propriedades.

Os AGD proporcionam uma maior liberdade de manuseio em uma figura, possibilitando aos usuários a construção, a manipulação e a visualização, de modo mais ágil, ajudando na formulação de suas justificativas na busca por soluções de problemas propostos. Segundo Bairral (2015), em relação aos recursos manipulativos convencionais, um dos seus diferenciais é a possibilidade de clicar, arrastar e transformar uma figura, mantendo ou não as suas propriedades euclidianas. Desta forma, AGD podem contribuir com o aprendizado matemático, pois eles permitem a construção e o manejo de objetos matemáticos na tela do computador (PEREIRA, 2012). Tratamos teoricamente os AGD como espaço de reflexão, argumentação e construção colaborativa de relações geométricas (POWELL; PAZUCH, 2016).

AGD também favorecem a construção de conceitos e a compreensão de propriedades das figuras geométricas. Estudos destacam que, com a utilização de um AGD, o usuário possui liberdade para procurar soluções, fazer argumentações (SCHEFER; PASIN, 2013), testar hipóteses (RICHT et al., 2012), criar conjecturas (BACCALINI-FRANK, 2012), deduzir propriedades matemáticas de modo ascendente ou descendente ${ }^{1}$ (ARZARELLO et al., 2002) e criar estratégias variadas (GRAVINA, 1996). Portanto, promover o movimento intrínseco da exploração até as justificativas matemáticas (POWELL; PAZUCH, 2016) pode contribuir para que professores, formadores e pesquisadores em Educação Matemática percebam o potencial do uso de AGD. De tal modo, este movimento pode contribuir para melhorar a aprendizagem em geometria, envolvendo professores e futuros professores no incremento de ideias matemáticas, por meio da colaboração online.

Zulatto, citada em Amaral (2011), divulga um estudo que analisou potencialidades de software de geometria dinâmica relatadas por professores de Matemática que o utilizaram em suas aulas. Os docentes destacaram como aspectos positivos a possibilidade de realizar construções geométricas, a promoção de atividades investigativas e de descobertas matemáticas, e a dinamicidade na visualização. Por exemplo, ao construir e arrastar as figuras é possível identificar as propriedades geométricas descobertas. Além disso, de acordo com os professores entrevistados,

\footnotetext{
${ }^{1}$ Ascendente (da construção para a teoria) e descendente (da teoria para a construção).
} 
quando conteúdos matemáticos são trabalhados com estes softwares, os alunos têm mais facilidade de observar as figuras, suas propriedades e invariantes.

Este artigo é fruto de uma pesquisa ${ }^{2}$ que tem como objetivo analisar contribuições de ambientes virtuais no aprendizado matemático. Em trabalho anterior (BARREIRA; BAIRRAL, 2016) exemplificamos atividades que elaboramos e estamos implementando com futuros professores de matemática no Virtual Math Team com o GeoGebra, o VMTcG. Neste, (i) analisamos uma dupla de licenciandos interagindo no VMTcG na resolução de uma tarefa com os propósitos de construir um quadrilátero e analisar a sua natureza, e (ii) refletimos sobre singularidades do VMTcG e sua possibilidade de uso na pesquisa ou no ensino com a Licenciatura em Matemática. Esperamos, com a análise discutida aqui, instigar uma possível relação entre a forma de raciocinar no VMTcG e o tipo de tarefa proposta.

\section{Interações em ambientes virtuais de aprendizagem}

Investigações com ambientes virtuais de aprendizagem (AVA) geralmente analisam interações síncronas e assíncronas. Na educação matemática brasileira embora a análise de chat tenha sido pioneira (BORBA; PENTEADO, 2001), o uso de fóruns de discussão tem predominado em estudos de formação continuada (XAVIER, 2016). A obra de Assis e Marques (2017) mostra outras possibilidades de análise, inclusive, com experiência síncrona no Facebook.

Assumimos interação como um processo comunicativo que objetiva o compartilhamento de significados entre os integrantes de um certo contexto de aprendizagem. Os envolvidos no processo interativo modificam as relações que se estabelecem no ambiente. Portanto, a interação não é uma cena estática, mas dinâmica (STAHL, 2009).

O aprendizado de um docente em exercício tem muita relação com a sua prática, particularmente, com as suas experiências com ensino ou com outros momentos concretos de aprendizagem dos alunos. Em um AVA o conhecimento profissional docente vai sendo (re)significado integrando às características do discurso e dos processos interativos de cada espaço comunicativo do cenário (BAIRRAL, 2007). Com isso, a interação deve desenvolver nos professores a estruturação de ações profissionais comprometidas com modificações nos processos de ensino e de aprendizagem. Isto é, além da reflexão, ela deve contribuir com mudanças em sua prática pedagógica e no seu próprio aprendizado (pessoal e profissional).

Em um AVA, o tipo de interação e os processos cognitivos a ele intrínsecos tem relação com o propósito pedagógico do ambiente. Nessa arquitetura, segundo Powell e Pazuch (2016), as tarefas requerem características próprias e que são diferentes daquelas voltadas para ambientes

\footnotetext{
${ }^{2}$ Pesquisa financiada pelo CNPq (bolsa PQ e IC).
} 
tradicionais de salas de aula, tais como: (i) construção, (ii) interação, (iii) significado matemático, (iv) questionamento, (v) engajamento, (vi) linguagem matemática e (vii) feedback, uma vez que o professor não está presente fisicamente no mesmo ambiente, sendo o contato entre o professor e aluno de modo indireto e em alguns eventos apenas virtual. Os autores lembram que para essa metodologia ter êxito no aprendizado é importante que se tenha uma permanência com algum tipo de registro gráfico, como o GeoGebra; seja uma ação responsável e comprometida; seja uma atividade espontânea, mas deliberada e sujeita a ser repensada, relida e revisada. Esses atributos do diálogo são necessários para que ele seja uma fonte para a aprendizagem e para a reflexão profunda.

\section{Aspectos metodológicos}

Estamos implementando e analisando interações de licenciandos em matemática da UFRRJ no $\mathrm{VMTcG}^{3}$.

\section{Caracterização do AGD síncrono}

Produzimos os dados da investigação no próprio VMTcG ${ }^{4}$. O VMTcG é um chat multirepresentacional (ÇAKIR; ZEMEL; STAHL, 2009) e as áreas que temos usado na pesquisa são (Figura 1): o quadro branco ${ }^{5}$ (espaço para construções, desenhos e demais inscrições), o GeoGebra (para construções geométricas) e a área de chat, que serve para interações escritas. O acesso ao ambiente $^{6}$ é gratuito, sendo preciso apenas realizar um cadastro para obter nome e senha de acesso.

Figura 1 - Imagem da sala do VMTcG

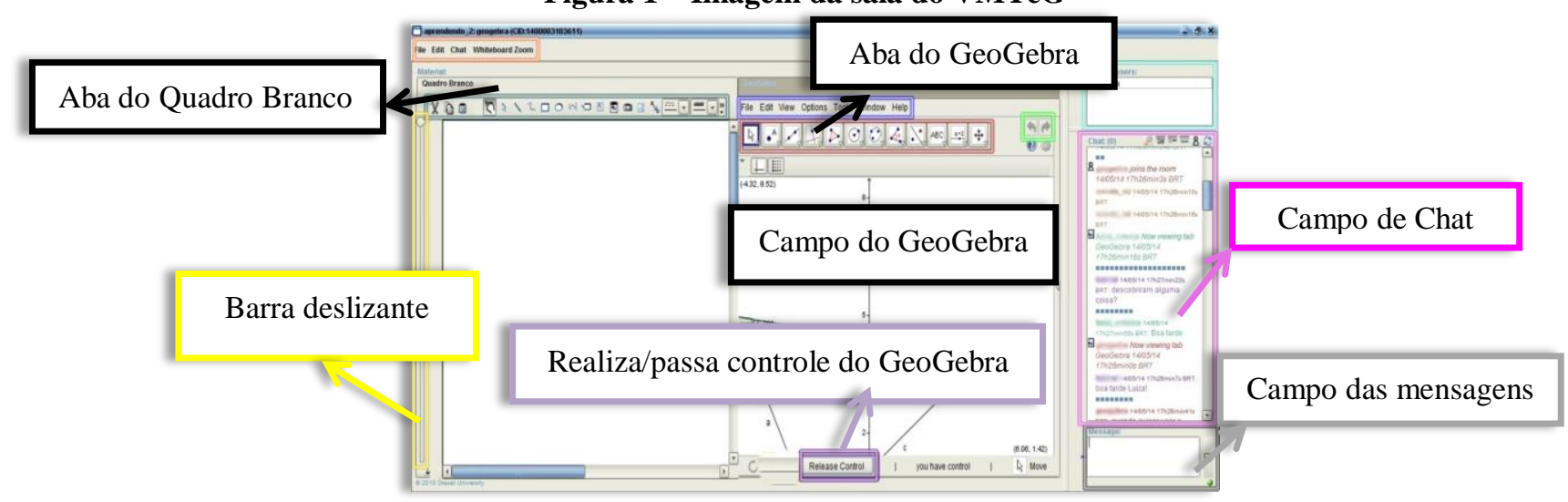

Fonte: Marques e Bairral (2016).

\footnotetext{
${ }^{3}$ No VMTcG para abrir o GeoGebra é necessário clicar na aba correspondente. Os participantes não podem usar concomitantemente o GeoGebra. É necessário pedir ao colega que libere o controle (take control).

${ }^{4}$ Desenvolvido por Gerry Stahl e sua equipe na Drexel University (Philadelphia, USA). Nossas interlocuções acadêmicas no uso do VMTcG também ocorrem na Rutgers University (Newark, New Jersey, EUA) com Arthur B. Powell e seu grupo de pesquisa. Aproveitamos para agradecer Arthur B. Powell pelas valiosas sugestões em uma versão anterior deste artigo.

${ }^{5} \mathrm{O}$ VMTcG inicia com o quadro branco e para abrir o GeoGebra é necessário clicar na aba correspondente. Essas duas áreas não são abertas simultaneamente.

${ }^{6} \mathrm{http} / / / \mathrm{vmt} . \mathrm{mathforum}$. org/VMTLobby/
} 
Bairral (2015) comenta algumas especificidades do VMTcG. O quadro branco possui ferramentas para inscrições variadas e similares a outros programas de desenho, por exemplo, o Word e o Paintbrush. O GeoGebra tem as mesmas funcionalidades de construção do GeoGebra 2D. A única diferença é que o $\mathrm{VMTcG}$ possui o botão Realize/take control (Realiza/Passa controle). O objetivo deste botão é que os integrantes das salas trabalhem no programa um de cada vez, ou seja, quando o usuário tem necessidade de construir algo ele solicita ao grupo o controle do programa. Tudo o que um integrante do ambiente fizer os outros acompanham, observando.

A Barra deslizante é outra ferramenta das salas do VMTcG. Ela mostra todo histórico construído no quadro branco ou no GeoGebra, deslizando a barra. Por exemplo, construíram um triângulo e um quadrado em uma sala. Para saber qual polígono foi construído primeiro, então, deslizando esta barra para cima ela desfaz tudo que foi feito no campo gráfico do GeoGebra e, para baixo, ela refaz toda a construção. Existe também um botão Add a Tab, cuja função é adicionar uma aba de algum recurso disponível no ambiente, como o GeoGebra e o quadro branco. A área do chat é dividida em três campos que são: campo de mensagens, de usuários e de chat. A finalidade do campo de mensagens é a escrita dos diálogos entre os integrantes da sala. Já o campo de usuários mostra quem está no ambiente. Por último, o campo de chat que registra a escrita dos participantes com sinalizadores temporais de interação e de outras ações feitas no quadro branco.

\section{Coleta e análise de dados}

Antes do trabalho específico nas tarefas propostas temos o momento da ambientação. Nele o graduando tem a oportunidade de se familiar com o VMTcG. Cada sala é considerada uma unidade de análise e não temos analisado as salas de ambientação. Geralmente o número de participantes em cada sala é quatro. Todavia, em algumas formações temos número mais reduzido em função do total de alunos a serem agrupados ${ }^{7}$. Há casos também em que estudantes previstos para a composição do grupo não acessam por problemas técnicos ou por não comparecimento online na hora programada.

Para coleta e redução de dados usamos: (i) tabelas geradas (pelo próprio VMTcG) e sua edição com os registros em outros espaços do ambiente; (ii) uso do VMT player, que permite revisita recorrente às interações em todo o ambiente; (iii) print de telas com construções no quadro branco ou na aba do GeoGebra; e (iv) anotações dos pesquisadores sobre algo que chamou atenção nas interações.

\footnotetext{
${ }^{7}$ Há casos também em que estudantes previstos para a composição do grupo não acessam por problemas técnicos ou por não comparecimento online na hora programada.
} 
Como dissemos, nas implementações propiciamos um tempo de ambientação ${ }^{8}$. É um momento - cerca de 30 minutos - no qual os interlocutores têm a oportunidade de se familiarizar com o ambiente virtual. $\mathrm{Na}$ sala (teste 2) propusemos a seguinte tarefa elaborada por nossa equipe de pesquisa, e que será objeto de análise neste artigo:

\footnotetext{
- Construa um segmento AB;

- Marque o ponto médio de $\mathrm{AB}$ (Ponto C);

- Por meio da ferramenta (Círculo dados centro e Um de seus pontos), construa duas circunferências de centro $\mathrm{A}$ e $\mathrm{B}$ e raio até o ponto médio $\mathrm{C}$. Com a mesma ferramenta faça uma circunferência de centro $\mathrm{C}$ que intercepte as extremidades A e B;

- Com a ferramenta (Interseção de dois objetos) marque as interseções entre as circunferências de centro A e B com a de centro C, desta forma os pontos D, G, E e F serão criados. A seguir, construa os segmentos AD, DG e GB. (Obs.: Na construção das circunferências clique nos pontos já existentes do segmento inicial, para não criar novos pontos).

- Manipule a construção, de os valores dos ângulos e dos lados. Qual é o quadrilátero em questão?

- Comente o que ocorre quando este é manipulado.
}

Trata-se de uma tarefa de natureza fechada ${ }^{9}$, sendo necessário conhecimento prévio de conceitos sobre quadriláteros, particularmente, relação entre ângulos, diagonais e tipos de quadriláteros. Por se tratarem de participantes que já possuíam familiaridade com geometria e por terem cursado três disciplinas de geometria, acreditamos que não foi preciso que algum dos participantes recorresse a pesquisas no momento da resolução.

A constituição da sala 2, analisada neste artigo, ficou assim:

Quadro 1- Constituição das salas 2

\begin{tabular}{|c|c|c|c|}
\hline & Início & Final & Participantes \\
\hline Sala 2 & $\begin{array}{c}14 \text { horas e } \\
34 \text { minutos }\end{array}$ & $\begin{array}{c}15 \text { horas e 53 } \\
\text { minutos }\end{array}$ & $\begin{array}{c}\text { Anderson e Manoel } \\
\text { Professor: Bairral }\end{array}$ \\
\hline
\end{tabular}

Fonte: Elaborado pelos autores.

Como objetivo da análise apresentada aqui ilustraremos interações ocorridas na sala de teste 2, que contou com a participação de dois graduandos: Anderson e Manuel. Os sujeitos tinham cursado as disciplinas Construções Geométricas, Geometria Euclidiana Plana e Tópicos de Geometria Espacial, obrigatórias da Licenciatura em Matemática.

\section{Licenciandos interagindo no VMT com GeoGebra}

Ilustramos a seguir a tela na qual os alunos interagiram na tarefa proposta (Figura 2).

\footnotetext{
${ }^{8} \mathrm{Na}$ ambientação alguns alunos tentaram se conectar ao ambiente virtual, mas tiveram algumas dificuldades para encontrar a sala especifica onde estava sendo realizada a atividade. Neste dia o VMT estava com problemas, pois não conseguíamos ver a realização da tarefa feita pelos dois participantes que se conectaram. A instalação do aplicativo Java também foi um problema para pelo menos um participante.

${ }^{9}$ Uma tarefa com foco em um conteúdo matemático específico e sem muitas possibilidades para investigações e outros desdobramentos.
} 
Figura 2 - Imagem da sala do VMTcG

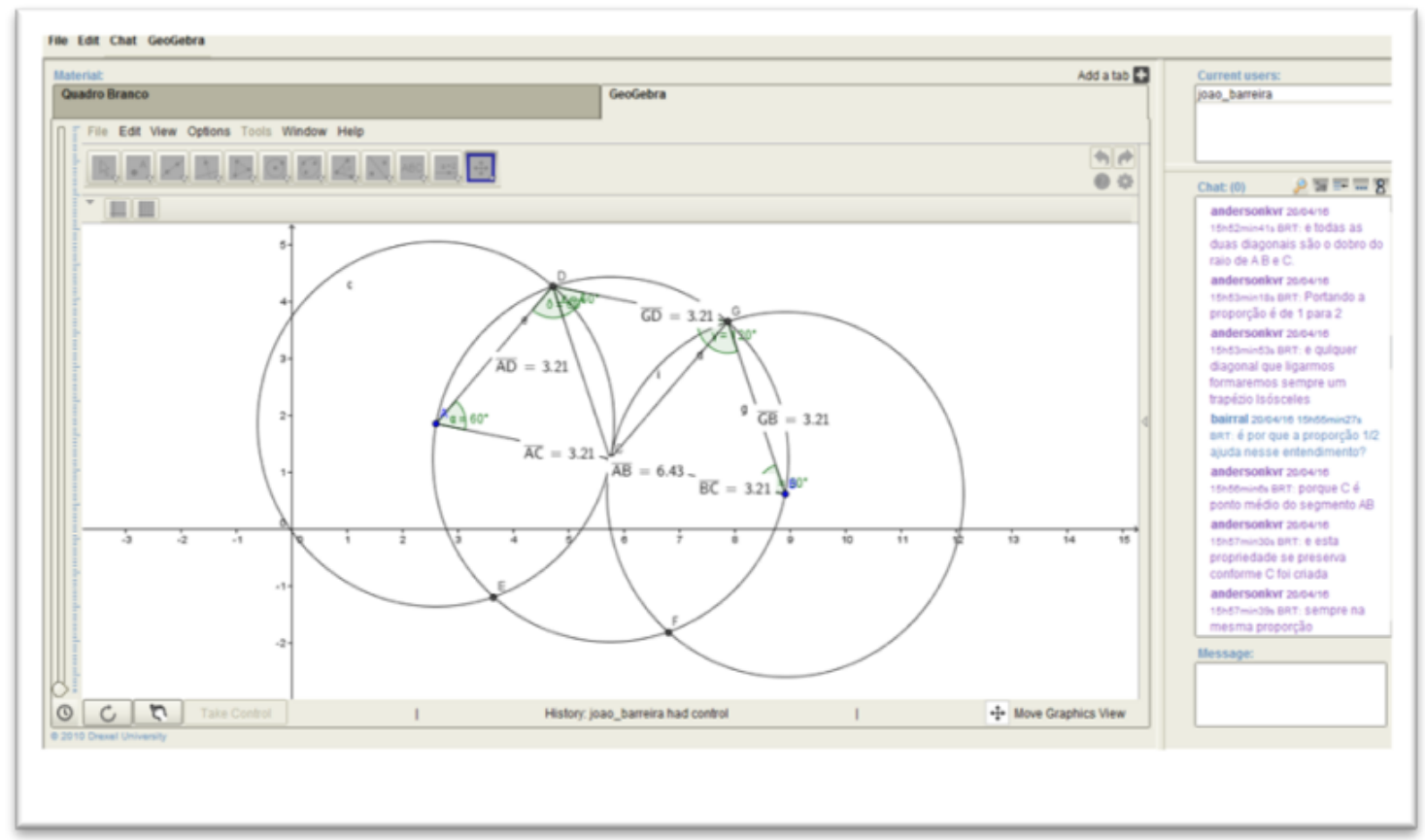

Fonte: PrintScreen da sala teste 2 do VMTcG.

Construindo o trapézio unido pelas circunferências, foram feitas algumas observações pelo participante Anderson e questionamentos feitos por Bairral, como ilustrados no trecho 17-33 do chat (Quadro 2).

Quadro 2 - Fragmentos de mensagens escritas na sala 2

\begin{tabular}{|c|l|l|}
\hline Índice & Autor & Mensagem \\
\hline 17 & Anderson & está correto? \\
\hline 18 & Anderson & a figura que se formou é um trapézio isósceles \\
\hline 19 & Bairral & o que vc acha manoel? \\
\hline 20 & Manoel & não estou conseguindo mexer \\
\hline 22 & Anderson & pq se o senhor reparar c \\
\hline 23 & Anderson & é ponto de médio do segmento AB \\
\hline 24 & Anderson & como AC=CB por definição \\
\hline 25 & Anderson & os raios da circunferências criadas são o mesmo \\
\hline
\end{tabular}

Fonte: Elaborado pelos autores a partir da planilha gerada pelo VMT.

Percebemos que o graduando Anderson após utilizar as ferramentas do GeoGebra obteve algumas importantes observações (26-33). Segundo Anderson (Quadro 3), a maneira como a circunferência $\mathrm{C}$ foi criada norteou toda a continuação da atividade, e claramente o fato de $\mathrm{C}$ possuir o mesmo raio que as circunferências A e B fez com ele conclui-se que se ligassem todas as 
interseções, construiriam um Hexágono Regular e que a relação entre as diagonais e o raio seria de 1 para 2.

Quadro 3 - Fragmentos de mensagens escritas na sala 2

\begin{tabular}{|c|c|c|}
\hline Índice & Autor & Mensagem \\
\hline 27 & Anderson & Se tomar os pontos de interseções entre as circunferências C A e B \\
\hline 28 & Anderson & Terá a mesma medida do raio da circunferência A B e C \\
\hline 29 & Anderson & $\begin{array}{l}\text { portanto se ligarmos todos os pontos formaremos um Hexágono } \\
\text { Regular de Lado cuja medida do lado é igual ao raio da circunferência } \\
\text { A B e C. }\end{array}$ \\
\hline 30 & Anderson & e todas a duas diagonais são o dobro do raio da A B e C. \\
\hline 32 & Anderson & Portanto a proporção é de 1 para 2 \\
\hline 33 & Anderson & $\begin{array}{l}\text { e qualquer diagonal que ligarmos formaremos sempre um trapézio } \\
\text { Isósceles }\end{array}$ \\
\hline
\end{tabular}

Fonte: Elaborado pelos autores a partir da planilha gerada pelo VMT.

No Quadro 4, após algumas perguntas o participante Anderson continua com suas observações, aprofundando-as como nas linha (54 e 55). Na linha 58 ele comenta sobre as condições importantes presentes no enunciado da tarefa para que fosse possível gerar o trapézio isósceles, "a circunferência $C$ ter centro no ponto médio de AB e a medida do seu raio ser igual a metade de $A B "$.

Quadro 4 - Fragmentos de mensagens escritas na sala 2

\begin{tabular}{|c|l|l|}
\hline Índice & Autor & Mensagem \\
\hline 44 & Bairral & e o que vc observam ao manipular a construção? Alguma curiosidade? \\
\hline 45 & Anderson & $\begin{array}{l}\text { as únicas coisas que percebo é que as relações permanecem para } \\
\text { quaisquer valores do segmento AB }\end{array}$ \\
\hline 46 & Anderson & a relação de 1 pra 2 sempre se mantém \\
\hline 47 & Anderson & e seus ângulos continuam os mesmos \\
\hline 48 & Anderson & Sempre teremos AD congruente a GB e GD \\
\hline 49 & Anderson & e AB sendo o dobro deles \\
\hline 50 & Bairral & e vc manoel? \\
\hline 51 & Bairral & vcs estão convencidos que é um trapézio? \\
\hline 52 & Anderson & Sim \\
\hline 53 & Manoel & estou sim \\
\hline 54 & Anderson & e o interessante é que se unirmos o ponto G ao C e D a C \\
\hline 55 & Anderson & temos 3 triângulos equiláteros congruentes \\
\hline 56 & Anderson & de lados cuja medida é o raio das circunferências \\
\hline 57 & Bairral & $\begin{array}{l}\text { então, que condições do enunciado foram importantes para que fosse } \\
\text { gerado o trapézio isósceles? }\end{array}$ \\
\hline 58 & Anderson & a circunferência C ter centro no ponto médio de AB e a medida do seu \\
\hline
\end{tabular}


\begin{tabular}{|l|l|l|}
\hline & raio ser igual a metade de $\mathrm{AB}$ \\
\hline Fonte: Elaborado pelos autores a partir da planilha gerada pelo
\end{tabular}

\section{Então, é quadrilátero?}

A tarefa proposta analisava a natureza de um objeto geométrico conhecido dos licenciandos: o quadrilátero. Podemos observar que os participantes da sala 2 conseguiram resolver a tarefa com certa facilidade, identificando relações que os levaram a algumas afirmações, como pode ser visto no Quadro 5.

Quadro 5 - Descrição do processo interativo da sala 2 na busca da resolução da tarefa

\begin{tabular}{|c|c|c|c|}
\hline \multicolumn{4}{|c|}{ Processo interativo de resolução da sala 2 da tarefa no VMTcG } \\
\hline Índice & Afirmativas & Conjecturas & $\begin{array}{l}\text { Propriedades } \\
\text { Geométricas }\end{array}$ \\
\hline 23 & $\begin{array}{l}\text { c é ponto médio do segmento } \\
\mathrm{AB}\end{array}$ & & \\
\hline 29 & & $\begin{array}{l}\text { portanto se ligarmos todos os pontos formaremos um } \\
\text { Hexágono Regular de Lado cuja medida do lado é } \\
\text { igual ao raio da circunferência A B e C. }\end{array}$ & \\
\hline 32 & & & $\begin{array}{l}\text { Portanto a } \\
\text { proporção é de } 1 \\
\text { para } 2\end{array}$ \\
\hline 33 & $\begin{array}{l}\text { e qualquer diagonal que } \\
\text { ligarmos formaremos sempre } \\
\text { um trapézio Isósceles }\end{array}$ & & \\
\hline 48 & $\begin{array}{l}\text { Sempre teremos AD congruente } \\
\text { a GB e GD }\end{array}$ & & \\
\hline 55 & & & $\begin{array}{l}\text { temos } 3 \\
\text { triângulos } \\
\text { equiláteros } \\
\text { congruentes }\end{array}$ \\
\hline
\end{tabular}

Fonte: Elaborado pelos autores.

As interações dos licenciandos ocorriam natural e simultaneamente, com inserções e justificativas no chat e nas construções no GeoGebra. Os participantes trabalharam em uma mesma figura, às vezes apagavam, mas reconstruíam e retornavam à construção inicial. Quando um licenciando movimentava no GeoGebra, o outro tinha a visualização simultânea do que acontecia. Quando um graduando queria realizar alguma construção ou manipulação no GeoGebra, ele solicitava o mouse, usando o comando passa o controle. Todo o processo de movimentação e exploração era observado na tela por todos os integrantes da sala.

Mesmo sendo uma atividade aparentemente simples do ponto de vista matemático, as interações trouxeram elementos interessantes para as descobertas dos graduandos, por exemplo, "portanto se ligarmos todos os pontos formaremos um Hexágono Regular de Lado cuja medida do 
lado é igual ao raio da circunferência $A$ B e C.” (linha 29), “... as relações permanecem para quaisquer valores do segmento AB" (linha 45), e "e qualquer diagonal que ligarmos formaremos sempre um trapézio isósceles" (linha 33).

A participação mais intensa do Anderson em relação a do Manuel não significa um maior domínio de conhecimento matemático. Talvez, o que possa interferir nesse processo seja a familiaridade com o GeoGebra, que era considerada boa para o Anderson e regular para o Manuel, ou, ainda, uma peculiaridade na personalidade do Manuel, que era muito tímido. Além disso, o tempo dedicado à resolução da atividade, o formato simultâneo de comunicação (mensagens escritas, inserções no quadro branco e construções no GeoGebra) oferecido pelo VMT e a dinâmica síncrona exigem maior familiaridade com o ambiente. A conexão lenta da Internet muitas vezes é um limitador em nossas implementações, pois a velocidade no entorno da UFRRJ nem sempre é estável e boa para a performance do VMTcG.

Finalmente, a dificuldade na organização mais sistemática de uma justificativa não é uma particularidade desses graduandos, pois sabemos que se trata de um processo difícil e que também demanda prática no VMTcG. Conforme sinalizaram Marques e Bairral (2014) a realização de apenas um chat pode não ser suficiente para esgotar uma discussão ou para dar conta da solução de um problema matemático ou da construção de uma determinada prova. Na dinâmica interativa no VMTcG, exploração, conjeturas e convencimentos estão em processo coletivo constante de refinamento.

\section{Considerações finais}

Neste artigo ilustramos interações de dois licenciandos em matemática na resolução de uma atividade com o propósito de construir e analisar a natureza de um quadrilátero. Embora tenhamos ilustrado interações de apenas uma dupla, cabe destacar que, no VMTcG, a geração de material bruto para análise é muito grande, pois o ambiente salva tudo o que é registrado em cada espaço interativo. Além do mais, as construções no GeoGebra são muitas e a recorrência ao player $^{10}$ é muito instigante na análise.

A análise mostrou que o modo de justificar dos licenciandos caminhou no sentido de observar a construção na tela e, a partir dela, aprimorar suas formas de convencimento. Sua estratégia de raciocínio esteve pautada no modelo descendente (ARZARELLO et al., 2002), ou seja, de propriedades geométricas conhecidas para a construção na tela. Embora a interação tenha sido frutífera, não emergiram ideias geométricas novas ou que tenham instigado a dupla a mudar a sua

\footnotetext{
${ }^{10}$ Veja um exemplo em http://www.gepeticem.ufrrj.br/portal/materiais-curriculares/pontos-notaveis-de-um-triangulo/
} 
linha argumentativa. Cabe investigar mais sobre o tipo de tarefa e a forma de raciocínio (ascendente ou descendente) que a mesma pode deflagrar.

Bairral e Marques (2016) enfatizam que as descobertas dos licenciandos foram diferentes na sala em que havia a construção, daquela que não possuía. Os autores instigam que descobertas matemáticas mais sofisticadas podem ocorrer em salas com a construção já fornecida. Cabe, portanto, investigar mais a validade deste resultado. Além do mais, a dinâmica interativa síncrona (com construções no GeoGebra, com inscrições no quadro branco e com registros escritos no chat) e de revisita assíncrona ao $\mathrm{VMTcG}$ podem incentivar os futuros professores a utilizar mais os AGD como minimizadores de dificuldades que encontramos para demonstrar em matemática, por exemplo.

Interações para resolução de uma tarefa proposta no VMTcG envolvem entendimento de procedimentos e de construção geométrica, de levantamento e análise de conjectura, de refinamento de propriedades e de construção de uma justificativa matematicamente convincente que possua embasamento teórico com base nas propriedades da Geometria Euclidiana. Powell e Pazuch (2016, p. 193) sublinham que:

as justificativas geométricas usadas pelos professores foram baseadas no uso de medidas. No entanto, na Geometria Euclidiana sintética (sem coordenadas), as proposições devem ser estabelecidas teoricamente com base nas propriedades dos objetos geométricos e das relações que existem entre eles. As conjecturas só podem ser confirmadas com o uso das relações e não das medidas. Isto porque as medidas são imprecisas e dependem das ferramentas usadas para medição. Em contraste, usando a mesma tarefa, apresentamos como professores, colaborativamente, estabelecem relações geométricas para elaborar justificativas teóricas. As interações entre eles ocorreram no ambiente VMTcG.

Em matemática, justificar - por escrito, organizado e convincentemente - é importante e muitas vezes difícil para os graduandos. Observando nossos dados de pesquisa, podemos perceber que, com a utilização do VMTcG, os licenciandos puderam gerar conjecturas e observar propriedades, e conceitos que foram emergindo naturalmente durante a interação. A possibilidade de verificar a validade ou não se torna mais rápida mediante a dinamicidade favorecida pelo ambiente, conforme quadro a seguir.

Quadro 6 - Fragmentos de mensagens escritas na sala 2

\begin{tabular}{|c|l|l|}
\hline 29 & Anderson & $\begin{array}{l}\text { portanto se ligarmos todos os pontos formaremos um Hexágono Regular de } \\
\text { Lado cuja medida do lado é igual ao raio da circunferência A B e C. }\end{array}$ \\
\hline
\end{tabular}

Fonte: Elaborado pelos autores a partir da planilha gerada pelo VMT.

As possibilidades que surgem para o caminho da justificativa são várias, pois a interação dinâmica entre os sujeitos e as ferramentas do VMTcG proporcionam ao participante um artifício de revisão, refinamento e avaliação constante do processo de raciocínio. Esta revisita (individual ou 
coletiva) pode ser inclusive, utilizada como estratégia de avaliação do próprio aprendizado. Por meio da ferramenta Player o estudante pode reorganizar todo o seu raciocínio e anotar passo a passo toda a sua estratégia de justificativa e, inclusive, aprimorar a sua escrita matemática.

A vivência formativa ocorrida no VMTcG contribui para que os discentes interajam online e percebam a importância (e a dificuldade) de justificar suas ideias em tarefas de geometria, mesmo que para alguns essa justificativa não seja simples (BAIRRAL; MARQUES, 2016). Esse tipo de pesquisa-intervenção na Licenciatura contribui com um novo olhar sobre os ambientes virtuais como mais uma possibilidade de inovação para as suas aulas de matemática.

Na figura seguinte (Figura 3), sintetizamos singularidades observadas nas interações dos licenciandos, quando uma tarefa de geometria é proposta de modo diferente em salas do VMTcG. Essas particularidades são: para a pesquisa, para a elaboração de tarefas, para o aprendizado de conceitos matemáticos, para as múltiplas formas de manifestação e negociação do discurso em situações de elaboração de justificativas matemáticas e para o tempo de reflexão online.

Figura 3 - Singularidades e contribuições do VMTcG em tarefas com e sem construção prévia

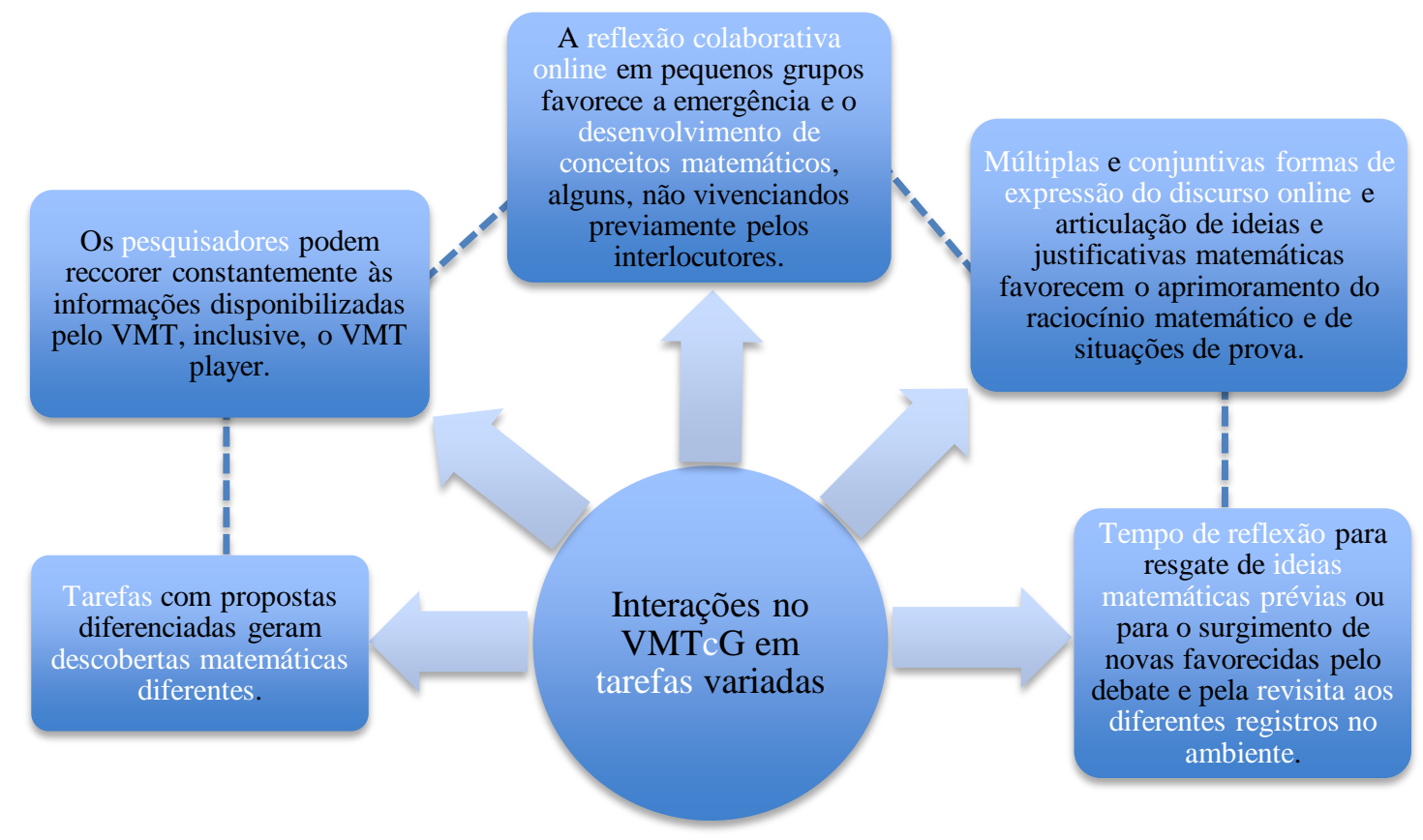

Fonte: Elaborado pelos autores.

Aos pesquisadores o VMTcG possibilita que revisitem constantemente todos os registros capturados pelo ambiente (BAIRRAL; POWELL, 2015). No que tange ao planejamento de atividades online cabe sinalizar que tarefas com propósitos distintos (de meras construções, de geração e verificação de conjecturas, de elaboração de provas etc.) geram discussões e descobertas matemáticas diferentes. Para o caso de uma tarefa mais fechada como a ilustrada e analisada neste 
artigo, foi possível observar que as interações estiveram circunscritas à análise de procedimentos, de propriedades e conceitos conhecidos pelos graduandos.

A naturalidade da reflexão online em pequenos grupos favorece a emergência e o desenvolvimento de conceitos matemáticos (MEIER; GRAVINA, 2012), mesmo que alguns não tenham sido estudados previamente pelos interlocutores. Este processo comunicativo de múltiplas e inter-relacionadas (ÇAKIR; ZEMEL; STAHL, 2009) formas de manifestação do discurso (escrito, pictórico, construção e exploração no GeoGebra etc.), de articulação de ideias e de construção de justificativas matemáticas, propicia o aprimoramento do raciocínio argumentativo dos sujeitos (SCHEFFER; PASIN, 2013). O tempo de reflexão - explícita ou implícita - (KINDEL, 2015), seja para o resgate de ideias prévias ou para o surgimento de novas, muitas vezes favorecido pela coletividade ou pela revisita aos diferentes registros no ambiente, também assume uma importância no aprendizado dos integrantes.

\section{Referências}

AMARAL, R. B. Argumentação matemática colaborativa em um ambiente online. Acta Scientiae, v.13, n.1, 2011.

ARZARELLO, F., OLIVERO, F., PAOLA, D.; ROBUTTI, O. A cognitive analysis of dragging practises in Cabri environments. ZDM, v. 34, n. 3, 66-72, 2002.

ASSIS, A., MARQUES, W. (Eds.). Ambientes virtuais e formação de professores: de construções individuais às interações coletivas (eBook) (Vol. 8). Seropédica: Edur, 2017.

BACCAGLINI-FRANK, A. E. B. Dragging and Making Sense of Invariants in Dynamic Geometry. In this activity, students learn to make conjectures about properties that do not change.

Mathematics Teacher, v. 105, n. 8, 2012.

BAIRRAL, M. A.; POWELL, A. Identificação e análise de objetos e relações em Virtual Math Teams. In A. POWELL (Ed.), Métodos de Pesquisa em Educação Matemática: Usando Escrita, Vídeo e Internet (p. 127-150). Campinas: Mercado de Letras, 2015.

BAIRRAL, M. A. Licenciandos em matemática analisando o comportamento de pontos notáveis de um triângulo em um ambiente virtual com GeoGebra. Anais ... 37 Reunião Nacional da ANPEd 04 a 08 de outubro de 2015, UFSC - Florianópolis, p. 1-20.

BAIRRAL, M. A. Discurso, interação e aprendizagem matemática em ambientes virtuais a distância. Rio de Janeiro: Edur, 2007.

BAIRRAL, M. A.; MARQUES, F. de J. R. Onde se localizam os pontos notáveis de um triângulo? Futuros professores de matemática interagindo no ambiente VMT com GeoGebra. Educação

Matemática Pesquisa, v. 18, n. 1, p. 111-130, 2016. Disponível em: http://revistas.pucsp.br/index.php/emp/article/view/24076/pdf.

BARREIRA, J. C.; BAIRRAL, M. A. Licenciandos em matemática trabalhando em ambiente virtual com o GeoGebra. Anais ... XIII ENEM, São Paulo, 2016.

http://sbem.bruc.com.br/xiienem/pdf/5630_2963_ID.pdf

BORBA, M. de. C.; Penteado, M. G. Informática e Educação Matemática. Belo Horizonte: Autêntica, 2001. 
ÇAKIR, M. P.; ZEMEL, A.; STAHL, G. The joint organization of interaction within a multimodal CSCL medium. International Journal of Computer-Supported Collaborative Learning, v. 4, n. 2, p. 115-149, 2009.

GRAVINA, M. A. Geometria Dinâmica uma Nova Abordagem para o Aprendizado da Geometria. In: Anais... VII Simpósio Brasileiro de Informática na Educação, p.1-13, Belo Horizonte, 1996.

KINDEL, D. S. Diálogos de alunos sobre infinito. Curitiba: Appris, 2015.

MARQUES, F. J. R; BAIRRAL, M. A. Futuros Professores de Matemática Interagindo em um Ambiente Virtual com o GeoGebra. Educação Matemática em Revista, Sociedade brasileira de educação matemática, p. 5 - 18. Brasil, 2014.

MEIER, M.; GRAVINA, M. A. Modelagem no GeoGebra e o desenvolvimento do pensamento geométrico no Ensino Fundamental. In: Anais ... CONFERÊNCIA LATINOAMERICANA DE GEOGEBRA, 2012, São Paulo. p. CCL-CCLXIV, 2012.

PEREIRA, T. de L. M. O uso do software GeoGebra em uma Escola Pública: interações entre alunos e professor em atividades e tarefas de geometria para o ensino fundamental e médio. Dissertação (Mestrado em Educação Matemática). Juiz de Fora: UFJF, 2012.

POWELL, A. B.; PAZUCH, V. Tarefas e justificativas de professores em ambientes virtuais colaborativos de geometria dinâmica. Zetetiké, v. 24, n. 2, p. 191-207, 2016.

RICHIT, A.; BENITES, V. C.; ESCHER, M. A.; MISKULIN, R. G. S. Contribuições do software GeoGebra no estudo de cálculo diferencial e integral: uma experiência com alunos do curso de geologia. In: Anais... 1ª . Conferência Latino Americana de GeoGebra, p. 90- 99, 2012.

STAHL, G. Studying virtual math teams. New York: Springer, 2009

SCHEFFER. N. F.; PASIN, P. A argumentação de professores de matemática suscitada pelo uso de softwares dinâmicos: construindo significados. Vidya, v. 33, n. 1, p. 9-17, 2013.

XAVIER, G. P. de O. Formação continuada para a EJA: Análise de interações docentes em matemática em um fórum de discussão. Dissertação (Mestrando em Educação). Seropédica: UFRRJ/PPGEDUC, 2016.

ZULATTO, R. B. A. Professores de Matemática que Utilizam Softwares de Geometria

Dinâmica: suas características e perspectivas. 2002. Dissertação (Mestrado em Educação Matemática). Rio Claro: UNESP, 2002. 